\title{
Edukasi Pencegahan Penularan Penyakit Tb Melalui Kontak Serumah
}

\author{
Rismawati Pangestika $^{1 *}$, Rina Khairunnisa Fadli ${ }^{1}$, Rony Darmawansyah Alnur ${ }^{1}$ \\ ${ }^{1}$ Fakultas Ilmu-Ilmu Kesehatan Universitas Muhammadiyah Prof. DR. Hamka, Jakarta, Indonesia, 12130 \\ *Email korespondensi:: rismawati_pangestika@uhamka.ac.id
}

\begin{abstract}
Abstrak
Keluarga merupakan unit masyarakat terkecil yang dapat sangat beresiko lebih cepat dalam penularan penyakit TB. Kasus TB anak di antara kasus baru Tuberkulosis Paru di kota Tangerang Selatan yang tercatat sebesar 8,33\% menduduki peringkat ke-3 di Provinsi Banten menunjukkan bahwa penularan kasus Tuberkulosis Paru BTA Positif kepada anak cukup besar. Sedangkan angka kematian akibat penyakit TB selama pengobatan sebanyak 19 orang (sama dengan jumlah kematian TB di Kabupaten Serang) menduduki peringkat 4 di provinsi Banten. Salah satu upaya pencegahan penularan TB melalui kontak antar anggota keluarga adalah dengan melakukan edukasi tentang penyakit TB dalam hal gejala, penularan dan pencegahan penyakit TB melalui PHBS (Perilaku Hidup Bersih dan Sehat) melalui media poster maupun leaflet serta Pemberian Makanan Tambahan (PMT) dan masker kepada keluarga pasien TB di Kelurahan Bambu Apus, Kecamatan Pamulang, Kota Tangerang Selatan. Hasil kegiatan ini menunjukkan adanya peningkatan pengetahuan responden tentang peningkatan pengetahuan penyakit TB $(71,4 \%)$, mekanisme penularan penyakit TB $(71,4 \%)$, pengobatan penyakit TB $(80 \%)$ dan cara pencegahan TB dengan PHBS (100\%) dengan rata-rata total peningkatan pengetahuan sebesar $80,7 \%$. Diharapkan peningkatan kualitas hidup bersih dan sehat dalam upaya pencegahan penularan TB akan semakin meningkat untuk kualitas hidup yang lebih baik dalam bidang kesehatan.
\end{abstract}

Kata Kunci: Edukasi, tuberkulosis, kontak serumah, PHBS

\begin{abstract}
Family is the smallest community unit that can be at a higher risk of transmission of TB. Cases of TB in children among new cases of Pulmonary Tuberculosis in the city of South Tangerang which was recorded at $8.33 \%$ was ranked $3^{\text {rd }}$ in Banten Province indicating that the transmission of cases of Positive AFB Lung Tuberculosis to children was quite large. While the death rate due to TB during treatment as many as 19 people (the same as the number of $T B$ deaths in Serang District) was ranked 4th in Banten province. One of the efforts to prevent $T B$ transmission through contact between family members is by educating about TB disease in terms of symptoms, transmission and prevention of TB disease through PHBS (Clean and Healthy Life Behavior) with poster and leaflet media and Supplementary Feeding (PMT) and masks to families of TB patients in Bambu Apus Village, Pamulang District, South Tangerang City. The results of this activity indicate an increase in respondents' knowledge about increased knowledge of TB disease (71.4\%), the mechanism of transmission of $T B$ disease (71.4\%), treatment of TB disease (80\%) and how to prevent TB with PHBS (100\%) evenly The total increase in knowledge was $80.7 \%$. It is expected that the improvement of the quality of clean and healthy life in an effort to prevent TB transmission will increase for a better quality of life in the health sector.
\end{abstract}

Keyword: Prevention, tuberculosis, housing contact, clean healthy lifestyle

Format Sitasi: Pangestika, R., Fadli, R.K., \& Alnur, R.D. (2019). Edukasi Pencegahan Penularan Penyakit TB melalui Kontak Serumah. Jurnal Solma, 8(2), 229-238. Doi: http://dx.doi.org/10.29405/solma.v8i2.3258

Diterima: 09 Januari 2019 | Revisi: 29 Juni 2019 | Dipublikasikan: 21 Oktober 2019 
(C) 2019. Oleh authors. Lisensi Jurnal Solma, LPPM-Uhamka, Jakarta. Artikel ini bersifat open access yang didistribusikan di bawah syarat dan ketentuan Creative Commons Attribution (CC-BY) license. (http://creativecommons.org/licenses/by/4.0/).

\section{PENDAHULUAN}

Tuberkulosis (TB) merupakan penyakit menular yang masih menjadi permasalahan di dunia kesehatan hingga saat ini. World Health Organization (WHO) melaporkan bahwa pada tahun 2017 terdapat 6,4 juta kasus baru penyakit TB yang dilaporkan dengan selisih 3,6 juta antara insiden dan kasus TB yang dilaporkan. Sepuluh negara menyumbang $80 \%$ dari selisih angka tersebut dengan persentase terbanyak $46 \%$ berasal dari tiga negara teratas yaitu India, Indonesia dan Nigeria. Sedangkan pada tahun 2018 terdapat delapan negara yang menyumbang 66\% kasus baru TB antara lain India, Cina, Indonesia, Filipina, Pakistan, Nigeria, Bangladesh dan Afrika Selatan. (WHO, 2018).

Berdasarkan data tahun 2016 menunjukkan bahwa kasus insiden TB secara global berjumlah 10,4 juta kasus yang setara dengan 120 kasus per 100.000 penduduk dengan perkiraan insiden TB sebesar 45\% ada di wilayah Asia Tenggara. Jumlah kasus baru TB di Indonesia pada tahun 2017 sebanyak 420.994 kasus dengan risiko berdasarkan jenis kelamin yaitu laki-laki memiliki risiko 1,4 kali lebih besar dibandingkan dengan perempuan. Sedangkan berdasarkan survei prevalensi, laki-laki 3 kali lebih tinggi dibandingkan dengan perempuan yang kemungkinan dikarenakan perilaku merokok dan kurangnya kepatuhan minum obat (Kementerian Kesehatan RI, 2018). Kasus TB semua tipe di Provinsi Banten pada tahun 2018 sebanyak 28.797 kasus yang menjadikan Banten sebagai peringkat ke-6 dari total 10 besar provinsi di Indonesia dengan kasus TB terbanyak. Berdasarkan data tersebut, jumlah angka penemuan kasus Case Detection Rate (CDR) sebesar 87,1\% dengan angka notifikasi kasus baru TB atau Case Notification Rate (CNR) sebesar 227 per 100.000 penduduk. Angka $C N R$ provinsi Banten tersebut masih lebih tinggi dibandingkan dengan angka $C N R$ se-Indonesia yaitu 193 per 100.000 penduduk (Kementerian Kesehatan RI, 2019).

Pasien TB BTA positif merupakan sumber penularan utama dari penyakit TB itu sendiri. Pada waktu batuk atau bersin, pasien menyebarkan kuman ke udara dalam bentuk percikan dahak (droplet nuclei). Sekali batuk dapat menghasilkan sekitar 3000 percikan dahak. Umumnya penularan terjadi dalam ruangan dimana percikan dahak berada dalam waktu yang lama. (Kemenkes RI, 2011). Sedangkan risiko peningkatan paparan TB terkait dengan jumlah kasus menular di masyarakat, peluang kontak dengan kasus menular, 
patogenisitas dahak sumber penularan, intensitas batuk, kedekatan kontak dengan sumber penularan, konsnetrasi atau jumlah kuman yang terhirup, usia seseorang yang terinfeksi, tingkat daya tahan tubuh sesorang misalnya infeksi HIV/AIDS dan malnutrisi (gizi buruk) serta faktor lingkungan terkait konsentrasi kuman di udara seperti ventilasi, sinar ultraviolet dan penyaringan udara (Kementerian Kesehatan RI, 2014).

Anggota keluarga dengan kasus TB BTA positif yang tinggal serumah merupakan kelompok masyarakat yang memiliki potensi paling rentan untuk tertular penyakit TB. Beberapa penelitian menunjukkan bahwa penularan tuberkulosis tidak hanya dapat menular pada orang dewasa namun juga pada anak balita yang seruma dengan penderita tuberkulosis. Hal ini karena beberapa dari anggota keluarga tersebut sangat sulit untuk menghindari kontak dengan penderita dan ketidaktahuan penderita maupun keluarga terkait cara penularan penyakit tuberkulosis ini.Tujuan dari pengabdian masyarakat ini adalah untuk memberikan edukasi cara pencegahan penularan penyakit TB antar anggota keluarga melalui perilaku hidup bersih dan sehat (PHBS) sekaligus sebagai upaya untuk menumbuhkan kepekaan dan kepedulian antar anggota keluarga dalam penyembuhan penyakit TB.

\section{MASALAH}

Angka kesembuhan penyakit TB di Kota Tangerang Selatan sebesar 89,37\% baik laki-laki ataupun perempuan termasuk kategori lebih baik dibandingkan total rata-rata angka kesembuhan tingkat provinsi Banten yang hanya sebesar 81,53\%. Namun, kasus TB anak di antara kasus baru Tuberkulosis Paru di kota Tangerang Selatan yang tercatat sebesar 8,33\% menduduki peringkat ke-3 di Provinsi Banten menunjukkan bahwa penularan kasus Tuberkulosis Paru BTA Positif kepada anak cukup besar. Sedangkan angka kematian akibat penyakit TB selama pengobatan sebanyak 19 orang (sama dengan jumlah kematian TB di Kabupaten Serang) menduduki peringkat 4 di provinsi Banten (Dinas Kesehatan Provinsi Banten, 2017).

Berdasarkan permasalahan tersebut, pemberian informasi dan edukasi terkait hal-hal yang perlu dilakukan dalam memutus mata rantai penularan TB karea beberapa masyarakat dan penderita tuberkulosis masih memiliki pengetahuan yang minim terkait hal-hal tersebut. Mitra pengabdian masyarakat ini adalah Pimpinan Daerah Aisyiyah Kota Tangerang Selatan yang pernah memiliki amal usaha bidang kesehatan dengan adanya Community TB Care sehingga diharapkan dapat membantu memberikan informasi dan edukasi dalam pencegahan 
penularan tuberkulosis sehingga diharapkan keluarga khususnya menjadi pelopor dalam memutus mata rantai penularan tuberkulosis. Masyarakat sasaran program kemitraan ini adalah masyarakat yang menderita TB di wilayah Puskesmas Bambu Apus. Upaya pencapaian perilaku kesehatan masyarakat yang sehat agar terhindar dari masalah tuberkulosis dapat dimulai dimasing - masing keluarga sehingga sangat penting untuk memberikan informasi dan edukasi terkait hal-hal yang perlu dilakukan agar rantai penularan tuberkulosis tidak berlanjut kepada keluarga serumah yang lain.

\section{METODE PELAKSANAAN}

Metode pelaksanaan kegiatan ini berdasarkan pada analisis situasi masyarakat Kelurahan Bambu Apus, Kecamatan Pamulang, Kota Tangerang Selatan antara lain edukasi secara door to door ke rumah penderita TB disertai dengan pemberian masker, makanan tambahan dan poster pencegahan penularan TB melalui Perilaku Hidup Bersih dan Sehat (PHBS). Pelaksanaan kegiatan ini dapat dilihat pada Tabel 1.

Tabel 1. Pelaksanaan Kegiatan Pengabdian Masyarakat

\begin{tabular}{ll}
\multicolumn{1}{c}{ Nama Kegiatan } & \multicolumn{1}{c}{ Bentuk Kegiatan } \\
\hline $\begin{array}{l}\text { Brainstorming pencegahan penularan } \\
\text { TB melalui kontak serumah }\end{array}$ & Diskusi dan sosialisasi dengan Kader Puskesmas \\
& \\
\hline $\begin{array}{l}\text { Edukasi pencegahan penularan TB } \\
\text { melalui kontak serumah }\end{array}$ & $\begin{array}{l}\text { Diskusi dan sosialisasi dengan penderita TB dan } \\
\text { keluarga }\end{array}$ \\
\hline Monitoring dan Evaluasi & $\begin{array}{l}\text { Diskusi dengan penderita TB dan keluarga dengan } \\
\text { melihat hasil pre-test dan post-test }\end{array}$ \\
\hline
\end{tabular}

\section{PEMBAHASAN}

Kegiatan penyuluhan diawali dengan koordinasi dengan pihak Puskesmas Bambu Apus didampingi kader Community TB Care 'Aisyiyah. Kegiatan selanjutnya dilakukan dengan mendatangi rumah pasien TB (door to door). Menurut data dari Puskesmas Bambu Apus, ada 9 pasien TB di Kelurahan Bambu Apus, namun pada pelaksanaanya hanya 7 pasien yang dapat didatangi rumahnya dikarenakan 2 pasien lainnya sering berpindahpindah domisili dan sulit untuk dihubungi. Sedangkan dari 7 rumah pasien TB yang didatangi, didapatkan 10 responden yang meliputi penderita TB maupun keluarganya seperti yang dijelaskan pada Tabel 2. 


\begin{tabular}{lc} 
Tabel 2. Karakteristik Responden $(\mathrm{n}=10)$ \\
\hline Karakteristik & $\%$ \\
\hline Umur & \\
$\leq 43$ & 90 \\
$>43$ & 10 \\
\hline Jenis Kelamin & \\
Laki-laki & \\
Perempuan & 40 \\
\hline Pendidikan & 60 \\
Tidak sekolah & \\
SD & 0 \\
SMP & 0 \\
SMA/STM & 50 \\
\hline Pekerjaan & 50 \\
IRT & \\
Karyawan & 60 \\
Pedagang & 10 \\
\hline
\end{tabular}

Media penyuluhan berupa leaflet dan poster yang dibagikan kepada masing-masing keluarga beserta pemberian makanan tambahan serta masker. Poster berisi tentang ajakan untuk mencegah penularan penyakit TB dengan cara penerapan Pola Hidup Bersih dan Sehat (PHBS) yang meliputi (1) Makan-makanan bergizi untuk meningkatkan daya tahan tubuh; (2) Mendapatkan suntikan vaksin BCG bagi anak usia dibawah 5 tahun untuk menghindari TB berat (Meningitis dan Miler); (3) Membuka jendela agar rumah mendapatkan sinar matahari dan udara segar; (4) Menjemur alas tidur agar tidak lembab; (5) Olahraga teratur; (6) Tidak merokok. Sedangkan leaflet berisi tentang beberapa sub-topik edukatif terkait materi TB antara lain: (1) Penyakit TB; (2) Penularan penyakit TB; (3)Gejala penyakit TB; (4) Perilaku Hidup Bersih dan Sehat (PHBS) di Rumah Tangga; (5) Cara pencegahan TB melalui PHBS. Hal ini sesuai dengan pernyataan Ifroh et al., (2019) bahwa penggunaan media komunikasi, informasi dan edukasi berupa leaflet sangat bermanfaat dalam pelaksanaan edukasi kepada masyarakat. Kumpulan gambar berdasarkan kehidupan seharihari dapat meningkatkan sikap dan kesadaran mengenai peristiwa atau kejadian yang mempengaruhi perilaku kesehatan masyarakat.

Pre-test dan post-test sebagai bahan evaluasi dilakukan dengan metode selfassessment, peserta menjawab sendiri kueisoner dengan panduan instruktur dari kader. Penyampaian materi dilakukan personal dengan keluarga ataupun penderita $\mathrm{TB}$, namun tidak semua anggota keluarga dapat hadir dikarenakan ada yang sedang bekerja. Kemudian setelah penyampaian materi dilakukan post-test untuk mengetahui seberapa jauh pemahaman 
responden tentang penyakit TB dan cara pencegahannya. Hasil pre-post-test menunjukkan bahwa terjadi peningkatan pengetahuan responden dari sebelum diberikan penyuluhan dan dengan setelah diberikan penyuluhan seperti yang dijelaskan pada Tabel 3.

Tabel 3. Jawaban pre-test dan post-test $(\mathrm{n}=10)$

\begin{tabular}{lccc}
\hline \multirow{2}{*}{ Kategori pertanyaan } & \multirow{2}{*}{$\begin{array}{c}\text { Jumlah } \\
\text { pertanyaan }\end{array}$} & \multicolumn{2}{c}{$\begin{array}{c}\text { Jawaban Responden yang Benar } \\
\text { (rata-rata) }\end{array}$} \\
\cline { 3 - 4 } & & Pre-test & Post-test \\
\hline Pengetahuan penyakit TB & 7 & $3(42,8 \%)$ & $5(71,4 \%)$ \\
Penularan penyakit TB & 7 & $3(42,8 \%)$ & $5(71,4 \%)$ \\
Pengobatan penyakit TB & 5 & $3(60 \%)$ & $4(80 \%)$ \\
Pencegahan TB dengan PHBS & 6 & $4(66,7 \%)$ & $6(100 \%)$ \\
\hline
\end{tabular}

Kegiatan ini cukup efektif dalam peningkatan pengetahuan penyakit TB $(71,4 \%)$, mekanisme penularan penyakit TB $(71,4 \%)$, pengobatan penyakit TB $(80 \%)$ dan cara pencegahan TB dengan PHBS (100\%) dengan rata-rata total peningkatan pengetahuan sebesar $80,7 \%$. Hasil pre-test dan post-test tersebut sesuai dengan hasil penelitian Mayasari and B. Wahyono (2016) yang menyatakan bahwa terdapat perbedaan bermakna antara selisih nilai pre-test dan post-test pada kelompok yang mendapatkan intervensi berupa penyuluhan tentang penyakit Pneumonia dengan disertai pembagian dan penjabaran dan penjelasan materi dari media booklet, artinya pemberian penyuluhan dengan menggunakan media booklet efektif untuk meningkatkan pengetahuan. Edukasi terus menerus dapat membentuk sikap dan perilaku hygiene personal yang positif terkait pencegahan penularan penyakit TB antar anggota keluarga (Ernawati, 2018).

Tingkat pengetahuan responden terkait cara penularan penyakit TB tergolong masih kurang terkait kebiasaan / perilaku yang mudah menularkan TB, perilaku untuk mencegah penularan TB dan strategi pemerintah dalam menanggulangi penyakit TB yaitu DOTS (Directly Observed Treatment Shortcourse). Flex adalah istilah yang sering digunakan untuk menyebut penyakit TB (Setiadi and Adi, 2019). Sejalan dengan pernyataan tersebut, berdasarkan kategori pertanyaan pre-test dan post-test dapat diketahui bahwa rata-rata responden menjawab tentang penyebab penyakit TB adalah berasal dari debu kotor saja tanpa mengetahui bahwa sebenarnya ada bakteri atau kuman yang ada di udara, yaitu bakteri Mycobacterium tuberculosis. Sedangkan dalam kategori pertanyaan tentang penularan penyakit TB, banyak yang tidak mengetahui bahwa dengan membuang dahak di sembarang tempat juga menjadi perantara penularan penyakit TB. 
Program pengobatan TB dengan rentang waktu yang relatif panjang. Kelangsungan pengobatan ini sangat dipengaruhi oleh kualitas komunikasi interpersonal selama pengobatan, misalnya pelayanan yang ramah dan pemberian informasi yang jelas (Yuliastri, 2016). Rata-rata jawaban dari kategori pertanyaan pengobatan penyakit TB yaitu banyak yang tidak mengetahui bahwa pengobatan TB harus berkelanjutan selama 6 bulan dan tidak boleh terputus, karena jika terputus, maka harus memulai lagi dari nol bulan atau dari awal lagi. Oleh karena itu, diperlukan suatu komunikasi untuk meningkatkan pemahaman terhadap pasien TB beserta keluarganya agar patuh dalam pengobatan.

Pencegahan penularan TB dalam kategori lingkungan misalnya dalam bentuk konstruksi rumah. Melalui ventilasi, udara dapat keluar membawa M. tuberculosis dan mati terkena sinar ultraviolet. Tidak cukupnya luas ventilasi juga dapat meningkatkan kelembaban ruangan. Kelembaban ruangan yang tinggi akan menjadi media yang baik untuk tumbuh dan berkembang biaknya bakteri-bakteri patogen termasuk M. tuberculosis (Setiadi and Adi, 2019). Kelembaban yang tinggi disebabkan karena beberapa factor seperti kurangnya cahaya yang masuk kedalam rumah, jenis lantai, jenis dinding, dan ventilasi, sehingga dapat menyebabkan tingginya kelembaban pada ruangan. Pencahayaan yang kurang disebabkan karena kurangnya kesadaran untuk membuka jendela, gorden, dan pintu rumah. Kurangnya kaca pada atap rumah juga dapat mempengaruhi banyaknya sinar matahari yang masuk kedalam rumah. Sinar matahari juga tidak dapat masuk karena terhalang oleh dinding atau tembok rumah tetangga (Mulasari, 2019). Hal tersebut sesuai dengan kenyataan di lapangan bahwa kategori pertanyaan pencegahan TB dengan PHBS belum banyak diketahui oleh masyarakat, misalnya rutin membuka jendela setiap hari agar cahaya matahari masuk dan udara tidak lembab, karena baketri TB akan mati karena cahaya; memisahkan alat makan dan minum dengan penderita ; dan rutin menjemur alas tidur.

Penyuluhan atau pendidikan kesehatan dapat meningkatkan nilai rata-rata pengetahuan dari sebelum dan sesudah penyuluhan. Peningkatan pengetahuan tersebut akan diikuti juga peningkatan nilai rata-rata persepsi yang selanjutnya dapat mempengaruhi perilaku deteksi dini penyakit TB jika terus dilakukan follow-up perubahan perilaku minimal 3 bulan setelah intervensi melalui penyuluhan (Widyastuti, Agoes and Argadiredja, 2018). Dukungan dari keluarga yang baik dan positif adalah dengan berpartisipasi penuh pada proses pengobatan TB dan pencegahan penularan TB (Hutama, Riyanti and Kusumawati, 2019). Pemberdayaan keluarga (family empowerment) dapat meningkatkan self efficacy 
(keyakinan diri) dan self care activity (perawatan diri) keluarga dan penderita TB paru dalam perawatan penderita TB paru selama di rumah. Semakin tinggi self efficacy seseorang berdampak pada peningkatan self care activity orang tersebut (Muhtar, 2013). Oleh karena itu, penyuluhan melalui pemberdayaan anggota keluarga sangat diperlukan dalam upaya preventif pencegahan penyakit menular seperti tuberkulosis ini.

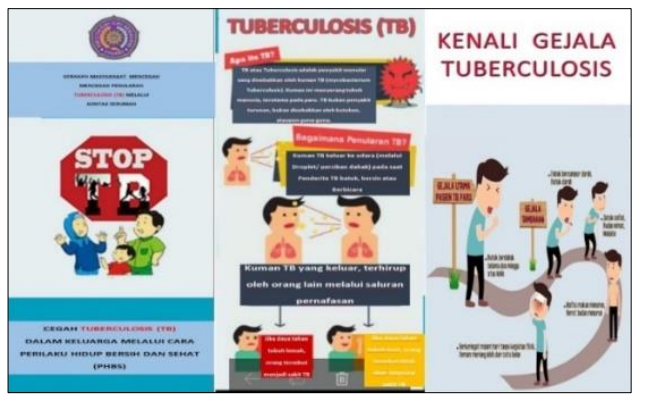

Gambar 1. Leaflet (halaman depan)

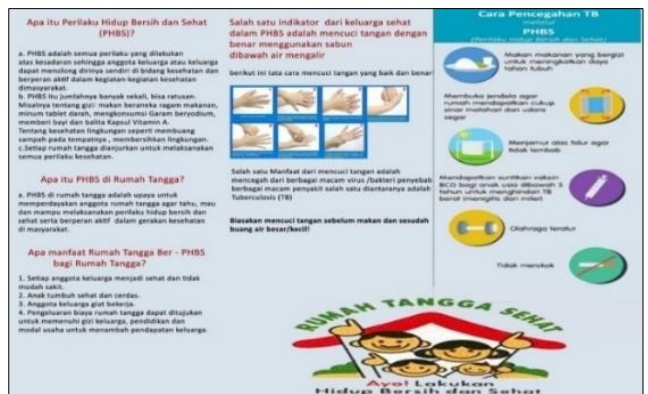

Gambar 2. Leaflet (halaman belakang)

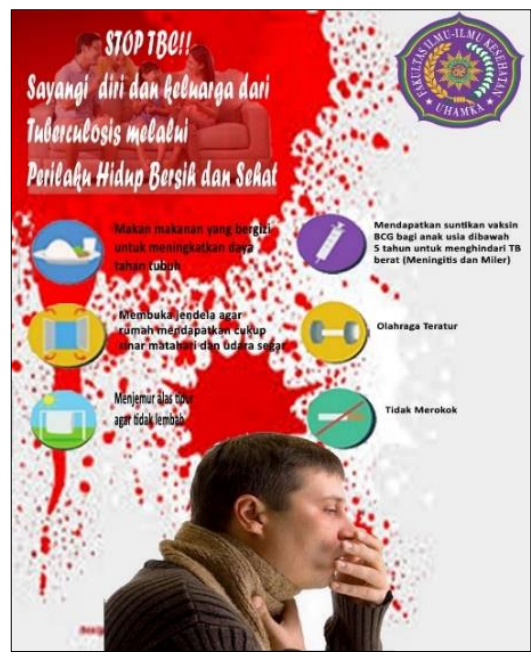

Gambar 3. Poster Pencegahan TB melalui PHBS

\section{KESIMPULAN}

Penyuluhan melalui media berupa poster ataupun leaflet dan pemberian makanan tambahan serta masker dalam kegiatan upaya pencegahan penularan TB antar anggota keluarga di Kelurahan Bambu Apus, Pamulang, Jakarta Selatan ini dinilai cukup efektif dalam meningkatkan pengetahuan tentang penyakit $\mathrm{TB}$, penularan penyakit $\mathrm{TB}$, pengobatan penyakit TB dan pencegahan penyakit TB melalui PHBS. Hal ini terlihat dari adanya peningkatan jawaban saat pre-test dan post-test. Kegiatan semacam ini dapat dilakukan secara berkelanjutan untuk mengetahui pemantauan kepatuhan pengobatan serta kebiasaan PHBS dalam pencegahan penularan penyakit TB. 


\section{UCAPAN TERIMA KASIH}

Ucapan terima kasih kepada LPPM UHAMKA sebagai penyandang dana kegiatan ini, Pimpinan Daerah 'Aisyiyah Kota Tangerang Selatan beserta Kader Community TB Care sebagai mitra kegiatan, pihak Puskesmas Kelurahan Bambu Apus dan Masyarakat Kelurahan Bambu Apus berperan dalam kegiatan ini.

\section{DAFTAR PUSTAKA}

Dinas Kesehatan Provinsi Banten (2017) 'Profil Kesehatan Provinsi Banten Tahun 2017'. Serang: Dinas Kesehatan Provinsi Banten.

Ernawati, K. et al. (2018) 'Penyuluhan Cara Pencegahan Penularan Tuberkulosis dan Pemakaian Masker di Keluarga Penderita: Pengalaman dari Johor Baru, Jakarta Pusat', Berita Kedokteran Masyarakat (BKM)Journal of Community Medicine and Public Health, 34(1), pp. 44-49.

Hutama, H. I., Riyanti, E. and Kusumawati, A. (2019) 'Gambaran Perilaku Penderita TB Paru dalam Pencegahan Penularan TB Paru di Kabupaten Klaten', Jurnal Kesehatan Masyarakat, 7(1), pp. 491-500.

Ifroh, R. H. et al. (2019) 'Peran Petugas Promosi Kesehatan dalam Penggunaan Audiovisual sebagai Media Komunikasi Informasi dan Edukasi’, Jurnal Ilmu Kesehatan, 7(2), pp. 281-289.

Kemenkes RI (2011) Pedoman Nasional Pengendalian Tuberkulosis. Jakarta: Kementerian Kesehatan.

Kementerian Kesehatan RI (2014) Pedoman Nasional Pengendalian Tuberkulosis, Pedoman Nasional Pengendalian Tuberkulosis. Jakarta: Kementerian Kesehatan RI.

Kementerian Kesehatan RI (2018) Info Data dan Informasi Tuberkulosis Tahun 2018. Jakarta.

Kementerian Kesehatan RI (2019) Profil Kesehatan Indonesia Tahun 2018. Jakarta.

Mayasari, M. L. and B. Wahyono (2016) . 'Efektivitas Penyuluhan Kesehatan dengan Metode Ceramah disertai Pemanfaatan Media Booklet dalam Upaya Meningkatkan Pengetahuan Ibu tentang Penyakit Pneumonia Pada Balita di Kelurahan Bandarharjo Kecamatan Semarang Utara Kota Semarang Tahun 2014', Unnes Journal of Public Health (UJPH), 5 Nomor 1, pp. 29-35.

Muhtar (2013) 'Pemberdayaan Keluarga dalam Peningkatan Self Eficacy dan Self Care Activity Keluarga dan Penderita TB paru’, 8(2), pp. 229-239.

Mulasari, S. A. (2019) 'Analisis Kesehatan Lingkungan Rumah, Penyuluhan dan Pelatihan Pencegahan Tuberkulosis ( TB ) di Bantul, Yogyakarta', Jurnal Pengabdian Pada Masyarakat, 4(2), pp. 119-128. doi: 10.30653/002.201942.97. 
Setiadi, D. and Adi, M. S. (2019) 'Pencegahan, Praktik Pencegahan dan Kondisi Rumah Pada Kontak Serumah dengan Penderita TB Paru di Kabupaten Demak', Jurnal Kesehatan Masyarakat, 18(April), pp. 36-45. doi: 10.13243/j.cnki.slxb.2013.05.013.

WHO (2018) Global TB Programme, End TB Accelerator Package. Switzerland.

Widyastuti, S. D., Agoes, R. and Argadiredja, D. S. (2018) 'Pengaruh Penyluhan tentang Penyakit TB Paru kepada Kontak Serumah terhadap Deteksi Dini Penyakit TB Paru di Puskesmas Wilayah Eks Kawedanan Indramayu Kabupaten Indramayu', Jurnal Kesehatan Indra Husada, 6(1), pp. 46-54.

Yuliastri, H. (2016) 'Efektivitas Komunikasi Interpersonal Petugas Kesehatan dengan Pasien TB Paru dalam Menjaga Kelangsungan Pengobatan di Puskesmas', Jurnal Komunikasi Bisnis dan Manajemen, 3(5), pp. 20-42. 